\title{
Real, rubber or virtual: the vision of "one's own" body as a means for pain modulation. A narrative review.
}

\section{Matteo Martini}

School of Psychology, University of East London, London, UK

Keywords: body ownership; body representation; pain; virtual reality; rubber hand illusion; visual analgesia; virtual hand illusion.

Correspondence should be addressed to

Matteo Martini

School of Psychology

University of East London

Water Lane

London E15 4LZ, UK.

E-mail: M.Martini@uel.ac.uk 


\begin{abstract}
In the last few years a branch of pain research has been focussing on the modulatory effects of the vision of the body on pain perception. So, for instance, the vision of one's own real body has been proven to induce analgesic effects. On the other hand, bodily illusions such as the rubber hand illusion have provided new tools for the study of perceptual processes during altered body ownership states. Recently, new paradigms of body ownership made use of a technology that is going places both in clinical and in experimental settings, i.e. virtual reality. While the vision of one's own real body has been proven to yield compelling analgesic effects, slightly more controversial are those attributed to the vision of "owned" dummy bodies. This review will discuss the studies that examined the effects on pain perception of the vision of the own body, with or without body ownership illusions.
\end{abstract}

\title{
Introduction
}

With more than six hundred thousand articles published on the topic, pain is certainly one of the best studied areas in the realm of medicine and neuroscience. Yet, due to its intrinsic subjective nature and the plethora of factors that may modulate it, much is left to be discovered. It is widely accepted that pain is both a sensorial and emotional conscious experience and it has a protective function, steering attention toward a potential threat, thus facilitating the avoidance of dangerous situations. However pain can also occur in the absence of actual tissue damage and "nociception and pain should not be confused, because each can occur without the other" (Loeser \& Treede, 2008). At the neural level, a set of brain areas have been identified as being specifically recruited to encode the pain experience. These areas form the so-called "pain matrix" and are commonly the primary and 
secondary somatosensory cortices (SI and SII), the insula, the anterior cingulate cortex (ACC), prefrontal cortex (PFC), thalamus, basal ganglia, and cerebellum (Schweinhardt \& Bushnell, 2010). The same brain areas have been shown to be active even during the observation of pain in others, in empathy for pain studies (Botvinick et al., 2005; Lamm, Batson, \& Decety, 2007; Saarela et al., 2007). Nevertheless, the existence of a specific set of brain areas selectively dedicated to encode the pain experience is still a matter for debate. The "pain matrix" has been lately challenged in favour of a neural network that mainly responds to salient stimuli, i.e. stimuli capable of engaging one's attention and motivational status, requiring the subject to make a prompt decision (Apkarian, Hashmi, \& Baliki, 2011). So, if on one hand evidence exist in favour of neural structures selectively responding to nociception and pain (Vierck, Whitsel, Favorov, Brown, \& Tommerdahl, 2013; Wager et al., 2013), on the other hand studies suggest that the activation of the putative "pain matrix" is prompted by all salient stimuli, regardless of the sensory channel involved (Mouraux \& Iannetti, 2009; Mouraux, Diukova, Lee, Wise, \& Iannetti, 2011). In such theoretical framework this salience-detection system would have a protective function detecting and reacting to possible threats, not merely painful, to ensure the physical integrity of the body (Legrain et al., 2012). Further reading on the theoretical frameworks about pain perception can be found in the historical overview of the main pain theories written by Moayedi \& Davis (Moayedi \& Davis, 2013).

The great interest in pain research can be easily explained by the fact that pain significantly represents a social and economic burden, as well as by the negative impact that it has on the sufferer's life. Indeed, not only is pain an unpleasant sensory and emotional experience but, in some cases, it can deeply affect person's life leading to suicidal ideation and behaviour (Campbell et al., 2015). Many studies have therefore attempted to find ways to manage pain states via pharmacological or non- 
pharmacological interventions. Of particular interest are the non-pharmacological interventions as they bypass the significant adverse side effects reported by conventional drug use (Carter et al., 2014). Belonging to this category are a series of studies that focussed their attention on the analgesic effects of cross-modal perception, for example pain and vision. In particular, from a seminal work with phantom limb pain published twenty years ago (Ramachandran \& RogersRamachandran, 1996), a series of studies in the pain research have concentrated their attention on the role played by the vision of one's own body in the modulation of pain. Bodily illusions like the rubber hand illusion (Botvinick \& Cohen, 1998) and its virtual counterpart (Sanchez-Vives, Spanlang, Frisoli, Bergamasco, \& Slater, 2010) have provided new avenues for investigating pain perception during body ownership paradigms. Exploiting the principle that, provided synchronous multisensory cues, one can feel a new fake body part as part of their own body, the feeling of body ownership can be extended to body parts that differ from the original. However, while the vision of one's own real body part has been shown to be analgesic (Longo, Betti, Aglioti, \& Haggard, 2009), there has been a recent debate on whether the analgesic effects of seeing one's own body part holds true also during the vision of fake (rubber/virtual) “owned” body parts (Gilpin, Bellan, Gallace, \& Moseley, 2014; Martini, Perez-Marcos, \& Sanchez-Vives, 2015).

The present work aims to review the research articles that so far have focussed on the effects on pain perception of the vision of one's own body, either real, rubber or virtual.

\section{The vision of one's own body in pain}

Cross-modal interactions between the vision of the body and somatosensation have been extensively investigated (Macaluso \& Maravita, 2010; Medina \& Coslett, 2010; 
Serino \& Haggard, 2010; Wesslein, Spence, \& Frings, 2014). A seminal study by Tipper for instance, showed how the vision of one's own body part influences tactile perception (Tipper et al., 1998). However, it was only 10 years after Tipper's work that the possible effects of the vision of the body were investigated regarding pain perception in non-amputees. In 2008, Valeriani and co-workers found that when their participants observed clips of another's hand receiving painful stimuli, while they concomitantly were getting painful laser stimulations on their hands, the early nociceptive-related neural processing was modulated, compared to the observation of the controlled stimuli (Valeriani et al., 2008). A step forward on this line was taken by Longo and collaborators in another laser-evoked potentials (LEPs) study (Longo, Betti, et al., 2009). In their work, these authors reported the first evidence that the vision of one's own body part in pain is analgesic. In three different experiments they showed how while their subjects were looking at their own painfully stimulated hand (but still keeping vision non-informative of the painful stimulation that was occurring), they felt less pain compared to when they were looking at a box or even at somebody else's hand. The analgesic effect related to the vision of their own body part was also accompanied by a reduction of the late $\mathrm{N} 2 / \mathrm{P} 2$ components of the LEPs (Longo, Betti, et al., 2009). The authors proposed that this effect was likely to be due to a visually-induced activation of the inhibitory GABAergic interneurons in the somatosensory areas. In support of this idea are the findings from a somatosensory evoked potentials investigation. Here Cardini and coworkers found that the vision of the hand, compared to the vision of a box, produced a suppression of the early somatosensory potential when two fingers were stimulated at the same time, thus revealing an augmented inhibitory interneuronal activity within the somatosensory cortex (Cardini, Longo, \& Haggard, 2011). This result was later supported by another EEG study showing that the vision of the body, 
compared to the vision of a neutral object, increased noxious-related beta oscillatory activity bilaterally in the sensorimotor cortices, likely reflecting cortical inhibitory activity of nociceptive stimuli processing (Mancini, Longo, Canzoneri, Vallar, \& Haggard, 2013).

Furthermore, in a following neuroimaging study, it was found that the vision of the body part subjected to painful stimulations increased the functional coupling between areas of the so-called "pain matrix" and the visual body network areas in the posterior parietal cortex and occipito-temporal areas (Longo, Iannetti, Mancini, Driver, \& Haggard, 2012b). Also, the vision of the hand led to a reduction in the activation of the primary somatosensory cortex and the operculo-insular cortex following painful stimuli (Longo, Iannetti, Mancini, Driver, \& Haggard, 2012a). Most importantly, the analgesic effects of the vision of the body seem to be sitespecific, so that less pain is felt only when looking at the body site where pain occurs (Martin Diers et al., 2013). Also, the visual modification (in size) of the body part observed, shapes the pain modulation according to whether the seen body part is enlarged or shrunk (Mancini, Longo, Kammers, \& Haggard, 2011a). However, results coming from studies changing the body part, size, are contradictory. For instance, it has been shown how the vision of a tinier hand seen through a convex mirror leads to a diminished heat pain threshold, while the vision of a bigger hand through a concave mirror increases heat pain threshold (Mancini et al., 2011a). Likewise a recent study showed that the visual magnification of the stimulated hand led to a reduced unpleasantness related to the painful stimulation, accompanied by a reduced physiological response (SCR) (Romano \& Maravita, 2014). Nevertheless, a study conducted on chronic pain patients reported the opposite results. Here the vision of their magnified hand, led patients with chronic hand pain to feel more pain during the movement of their limb while the vision of their shrunk hand reduced it 
(Moseley, Parsons, \& Spence, 2008). On the same line Diers and coworkers showed that the observation by chronic pain patients of their own downscaled back reduced their pain, while no effect was reported for the vision of an enlarged back (Martin Diers et al., 2013). The same result has been found by Ramachandran in a case study with a patient with phantom limb pain: a minimizing lens that gave the illusion that the lost left forearm was back there although shrunk, reduced the patients' pain, while a magnifying lens provided no pain modulation (Ramachandran, Brang, \& McGeoch, 2009). Conversely, regardless of the type of visual manipulation, osteoarthritis patients seem to benefit from either the illusion that their hand in pain is stretching or shrinking (Preston \& Newport, 2011). These contradictory results reported by studies on healthy subjects, as well as chronic pain patients, would point at a complex relationship between pain and the neural representation of the body. A possible explanation could reside in the altered neural representation of the body in chronic pain patients (Gilpin, Moseley, Stanton, \& Newport, 2015). So, a visual manipulation of the size of the body would induce a different effect in healthy subjects, with an intact body representation, compared to patients who have a representation of the body distorted (Tsay, Allen, Proske, \& Giummarra, 2015). Furthermore, it has been recently discovered that, to be effective in lowering pain intensity, the visual feedback relative to the body has to be "live" as in a real time video rather than static as in a picture, at least with chronic lower back pain patients (Diers, Löffler, Zieglgänsberger, \& Trojan, 2015).

Altogether these findings disclose an important modulatory effect of the vision of one's own body part while being in pain, both in healthy subjects for acute pain models and in patients with chronic pain. However, the representation of the body not only can be altered in patients, but it can also be manipulated experimentally in healthy subjects. For instance it is possible to incorporate a prosthetic arm in one's 
body schema (Mayer, Kudar, Bretz, \& Tihanyi, 2008). Moreover, fake body parts can be easily replaced with different versions of it, when it comes for example to their appearance. Therefore the question arises on whether the analgesic effect of the vision of one's own body are transferrable to new dummy "owned" body parts, and if and how the vision of an altered body, shapes the pain experience.

\section{Rubber hand illusion and pain}

With a simple experiment, Botvinick and Cohen demonstrated that intermodal matching between a touch felt on a hidden hand and a concomitant tactile stimulation seen on a rubber hand, led the majority of their participants to experience the so-called rubber hand illusion (RHI) (Botvinick \& Cohen, 1998). For the participants, this illusion brings about the feeling that the rubber hand is their own real hand (body ownership) (Botvinick \& Cohen, 1998). At the neural level this sensation is reflected by an increased blood oxygen level-dependent (BOLD) signal in the bilateral premotor cortex (Ehrsson, Spence, \& Passingham, 2004). Interestingly, such illusion is not constricted to the hand only, but it can be transferred to the whole body (Petkova \& Ehrsson, 2008; Petkova, Khoshnevis, \& Ehrsson, 2011).

Probably the first study to use the principles of the RHI on pain perception has been the one carried out by Valenzuela-Moguillansky and colleagues (ValenzuelaMoguillansky, Bouhassira, \& O'Regan, 2011). In two separate experiments the authors showed how, immediately after the RHI, pain ratings to painful heat stimuli decreased, while the mere observation of the rubber hand without any concomitant tactile stimulation did not yield such analgesic effect. Conversely, in the second experiment the authors found that the pain ratings were higher right after synchronous visuo-tactile stimulation (RHI), than after the asynchronous visuo- 
tactile condition, although this difference was not significant between conditions. They interpreted these controversial results taking into account different possible factors such as, among others, the 'violation of the expectation' taking place during the asynchronous condition (Lewis \& Lloyd, 2010), which would lead to disturbing and ambiguous sensations, possibly drawing more attention than during the normal RHI. Also, the authors called into play the role of different types of changes in the body schema of their participants, namely incorporating the rubber hand and disowning the real one. In this case, the vision of an "owned" rubber hand, painfully stimulated, would bring about higher pain ratings (Valenzuela-Moguillansky, Bouhassira \& O'Regan, 2011).

Body ownership illusions have not been limited to a rubber limb, but they have also been extended to whole bodies. Based on a slightly different type of experimental paradigm, Hansel and co-workers reported how by stroking the participants' back and a mannequin's back placed in front of them, the participants' pressure pain threshold increased as compared to when the participants looked at a non-corporeal object; moreover, the stronger the self-identification with the mannequin the higher the pain threshold (Hänsel, Lenggenhager, von Känel, Curatolo, \& Blanke, 2011). However, it should be pointed out that in this experiment there was a lack of correspondence between the body part seen (the mannequin's back) and the real body part receiving painful stimuli (the index finger). In addition, in the paradigm used by Hansel and co-workers the dummy body is seen from a third person perspective and this, along with multisensory correlations, can lead to the so-called Out of Body Experience (OBE) phenomenon (Ehrsson, 2007; Lenggenhager, Tadi, Metzinger, \& Blanke, 2007). It could be that, under these circumstances, the analgesic effect of seeing their own body part in pain may be mistaken for other analgesic effects, likely related to attentional mechanisms, or due to disownership (of 
the real body) processes taking place during the OBE (Guterstam \& Ehrsson, 2012). So, whether the analgesic effect of the vision of the body held true for the vision of an “owned” rubber hand, has yet to be properly ascertained. In two different experiments conducted by two independent labs, Mohan and colleagues reported that during the RHI, their participants failed to show a significant modulation of the heat pain as assessed by a visual analogue scale (VAS). Also their participants did not report a modulation of either heat or cold pain threshold (Mohan et al., 2012). However, in disagreement with Mohan's finding are the results of another RHI-pain study. Using three conditions in a within subjects design, Hegedus and collaborators found that both RHI and vision of the own hand resulted in slightly (but significantly) higher pain thresholds, compared to the asynchronous stroking control condition (Hegedüs et al., 2014).

Recently, the RHI paradigm was used to investigate its effects on the perceived discomfort caused by cold stimuli. In their experiment, Siedlecka and colleagues applied ice on the hand of their participants, right after the induction of the RHI (Siedlecka, Klimza, Łukowska, \& Wierzchoń, 2014). Two distinct groups of participants were considered, one experimental group where stroking was timely and spatially synchronized, and a control group where the stroking was spatially incongruent. The authors found that resistance time to cold stimulation increased and the sensation of discomfort decreased in the experimental group, compared to the resistance time and discomfort levels reached in the control group. Furthermore, the strength of body ownership illusion correlated positively with cold resistance time and with the experienced unpleasantness. These results would support Hegedus and colleagues' findings, according to which during the vision of an owned rubber hand the thermal pain threshold increases, similarly to what happens during the vision of one's own real body part in pain. Further support to these findings derive 
from an experiment with the RHI and the cold pressor test carried out by Giumarra and coworkers. In their experiment these authors found that pain tolerance significantly increases following the RHI compared to a control visuo-tactile asynchronous stimulation (Giummarra, Georgiou-Karistianis, Verdejo-Garcia, \& Gibson, 2015).

By promoting the feeling that a rubber limb is one's own real limb, the RHI would foster a reorganization of the body image with consequences on the perceptual processes (Longo, Schüür, Kammers, Tsakiris, \& Haggard, 2009). Indeed, the physical appearance of the rubber hand seems to play a major role in driving the modulatory effect of the vision of the body on pain perception. So, the analgesic effect of seeing the "own" body can be abolished, or can even lead to hyperalgesic effects (i.e., higher pain/increased sensitivity to pain), if the "owned" prosthetic hand looks injured. For instance, capsaicin-induced pain is worsened by the vision of an “owned” rubber hand that has a scar (Giummarra et al., 2015). Similarly, Osumi and colleagues found that the heat pain threshold significantly decreases when the “owned” rubber hand looks injured, not only compared to when it looks normal, but also when it is abnormally bent or very hairy (Osumi, Imai, Ueta, Nobusako, \& Morioka, 2014).

The majority of studies reported here suggest an analgesic effect of the vision of a rubber hand when the hand is incorporated into one's own body image. Further, the visual characteristics of the rubber hand could heavily modulate the ongoing pain. Nonetheless, further studies are needed to verify the presence of any causal relationship between the affective dimension of body image and pain perception. This could be facilitated by the usage of between- instead of within-subjects designs and by relying on statistical models that address causation, for instance, path analysis and structural equation modelling (Leppink, 2015). Research manipulating 
affect without changing visual appearance, and measuring the relation between affect and pain, independent of visual appearance, could also help explore whether there are any causal relations between the affective dimension of body image and pain perception.

\section{Virtual hand illusion and pain}

The term virtual reality (VR) was possibly used for the first time by Antonin Artaud in 1938 in dramaturgy (Artaud, 1938). However, the term as we currently mean it was first introduced in 1989 by Jaron Lanier (Lanier, J., Minsky, M., Fisher, S., Druin, A., 1989). Since then, many technological advances have been made in terms of computer processing speed, video quality and tracking systems. Nowadays, VR is no longer a prerogative of the entertainment field only, but it has finally found useful applications in teleoperation, psychotherapy, rehabilitation and behavioural neurosciences (Tarr \& Warren, 2002). Indeed, Immersive Virtual Reality (IVR) technology represents a powerful tool to generate sensory environments that can be replicated almost identically and that are under the full control of the experimenter ( Sanchez-Vives \& Slater, 2005).

At the beginning of this century, VR has been successfully introduced in pain management (Hoffman, Doctor, Patterson, Carrougher, \& Furness, 2000). For instance, it has been shown how playing a video game in VR makes adolescent and adult patients with burn wounds feel less pain during their treatments (Hoffman, Doctor, et al., 2000; Hoffman, Patterson, \& Carrougher, 2000). As objective evidence of VR analgesia, Hoffman and colleagues found in an fMRI brain scan study that VR greatly and significantly reduced pain related brain activity (Hoffman et al., 2004). A second fMRI study showed that the amount of pain reduction from VR was comparable to the analgesia from a moderate dose of hydromorphone pain 
medication (Hoffman et al., 2007). The analgesic properties of VR in this case have been largely attributed to its powerful distractive capacity, which would be higher than other similar non-VR interventions (i.e. video games on traditional PC screens), and would endorse an effective management of mild and severe pain states (Hoffman et al., 2011; Hoffman et al., 2014). In an elegant and comprehensive review by Malloy and Milling on the effectiveness of VR interventions for pain relief, it has been pointed out that immersive VR technology is more likely than non-immersive set ups to promote analgesia (Malloy \& Milling, 2010). The disparity between these two technologies in terms of pain outcomes would be greatly due to the distractibility given by the sense of presence, that refers to the feeling of being actually immersed in the virtual world, which would be much higher in immersive scenarios (SanchezVives \& Slater, 2005). The analgesic effectiveness of the immersive scenarios would be further improved by the usage of High-Tech helmets, which enables a wider fieldof-view, likely boosting the sense of presence and drawing more attentional resources (Hoffman et al., 2006). Additionally, not only the sense of presence influences the effectiveness of VR through distraction, but also anxiety as well as positive emotions such as fun, may affect the experience of pain during the VR exposure (for an extensive review on the topic, see Triberti, Repetto, \& Riva, 2014). For example, Maani and co-workers found that patients (soldiers with severe combat-related burn injuries) reported significantly less pain and rated fun during burn wound care significantly higher during VR (Maani et al., 2011). However, not only VR can be used to display virtual interactive scenarios that promote sense of presence and attentional engagement, but it has also been used effectively in the induction of the illusion of ownership over a virtual body (Bergström, Kilteni, \& Slater, 2016; González-Franco, Peck, Rodríguez-Fornells, \& Slater, 2014; Kilteni, Grau-Sánchez, Veciana De Las Heras, Rodríguez-Fornells, \& Slater, 2016; Kilteni, Maselli, Kording, 
\& Slater, 2015; Kilteni, Groten, \& Slater, 2012; Kilteni, Normand, Sanchez-Vives, \& Slater, 2012; Maselli \& Slater, 2013; Slater, Perez-Marcos, Ehrsson, \& Sanchez-Vives, 2008, 2009). Similar to what happens in the aforementioned RHI, during this illusion, participants feel a virtual body part as belonging to their own body, and this feeling can be extended to the entire virtual body (Maselli \& Slater, 2013). Such process can lead to profound psychological (Peck, Seinfeld, Aglioti, \& Slater, 2013) and perceptual (Banakou, Groten, \& Slater, 2013) consequences, as people react to it as if it was their own real body (Slater, Spanlang, Sanchez-Vives, \& Blanke, 2010). On this premise, Martini and colleagues tested the effect of virtual body ownership on pain perception. The authors showed how only during the vision of a virtual arm there was a substantial increase in the pain threshold as compared to the vision of either a virtual or a real object. Notably, the effect was not attributable to the mere observation of the virtual arm but, rather, the feeling of ownership over the virtual limb was crucial for the analgesic effect to emerge (Martini, Perez-Marcos, \& Sanchez-Vives, 2014). Therefore it seems that the analgesic effect of the vision of one's own body part in pain holds true even during the vision of a virtual body, provided that there is a feeling of ownership over it. Once again, the analgesic effect seems to be strictly connected with the visual properties of the body. So for instance, if the body visually fades away, also the pain sensation will be affected by it. This has been shown in a study where, in different conditions, the avatar's body was rendered with different levels of transparency. Here, the more the participants felt that the transparent virtual arm was their own limb, the lower was their heat pain threshold (Martini, Kilteni, Maselli, \& Sanchez-Vives, 2015). Therefore, similar to what has been found for rubber arms, the vision of an altered body can disrupt the emergence of the analgesic effect and it could even possibly drive hyperalgesic processes. However, there are other visual manipulations of the body that can interestingly 
reveal why such pain modulations occur. In an experiment using visual manipulations of the virtual body and thermal pain threshold, changes in colour of the virtual arm during ramps of heat painful stimuli drove the pain threshold of the participants according to the kind of colour displayed: the vision of a bluish "cold" arm led to a higher pain threshold as compared to a reddish "hot" arm, while a neutral green arm stood right in the middle (Martini, Perez-Marcos, \& SanchezVives, 2013). Exploiting the powerful association that colours have with temperatures, the vision of one's own arm changing colour has triggered top-down processes that differently modulated pain perception.

Recently Romano and co-workers reported that physiological responses to pain, as measured via SCR, are reduced when the participants look at the avatar's body from a first person perspective as compared to the vision of the avatar's body turned 90 degrees from the real. Moreover, in the same study the authors show how the physiological response is negatively correlated with the size of the virtual body, so that the bigger the body the lower the SCR (Romano, Llobera, \& Blanke, 2015). This result would support the effects of the vision of the own magnified body part on pain, which in healthy subjects would boost analgesia (Mancini et al., 2011a; Romano \& Maravita, 2014).

Fig 1 about here please-

\section{Conclusions}

Body and pain are strictly related, since the former is where the latter 'happens' and is at the same time perceived. Even the neural representation of the body seems to be quite critical in shaping the pain experience. For instance, many chronic pain patients report having a distorted representation of their affected body part (Gilpin et al., 2015; Melzack, 1990) and cortical misrepresentations of the body are associated 
with chronic pain states (Lotze \& Moseley, 2007; Preston \& Newport, 2011). However, it is not completely clear whether the vision of the body promotes a correct representation of the body via online visual feedback. Additionally, it is known how pain can be modulated by different psychological factors. In pain experiments involving the usage of a dummy body, these factors interact with the illusion of body ownership and with the physical properties of that body, modulating the pain output (fig.1). For instance patients with schizophrenia, as well as healthy subjects taking psychoactive drugs mimicking its symptoms, are more likely to experience the illusion of ownership over a rubber hand (Morgan et al., 2011; Peled, Ritsner, Hirschmann, Geva, \& Modai, 2000). At the same time anxiety, depression and anger are known to increase pain, while positive emotions usually decrease perceived pain (Peters, 2015). Cognitive factors such as attention, expectancy, appraisal and multisensory integrations can either increase or decrease pain and interact with emotional factors (see Peters, 2015; Senkowski, Höfle, \& Engel, 2014; Triberti et al., 2014, as recent reviews on these topics). The physical appearance of the body may also play a significant role. Indeed the vision of a distorted body appearance may modulate the body ownership levels (Martini, Kilteni, Maselli, \& Sanchez-Vives, 2015), but it may also affect psychological factors such as body image (Osumi, Imai, Ueta, Nobusako, et al., 2014) and modulate pain perception during illusory body ownership paradigms (Martini, Perez-Marcos, \& Sanchez-Vives, 2013; Martini, Kilteni, Maselli, \& Sanchez-Vives, 2015; Osumi, Imai, Ueta, Nobusako, et al., 2014; Osumi, Imai, Ueta, Nakano, et al., 2014) or in studies involving the vision of one's own real body (Mancini, Longo, Kammers, \& Haggard, 2011b; Romano \& Maravita, 2014).

Attention is certainly one of the most important factors in the modulation of pain (Legrain et al., 2009). Yet, the analgesic effect linked to the vision of one's own body 
is far from merely being due to distraction mechanisms. Interestingly, it has been proposed that such effects entail the shaping of the somatosensory maps in the primary somatosensory cortex, through an increase in the intracortical inhibition (Haggard, Iannetti, \& Longo, 2013). Studies relying on bodily illusions, either taking into account rubber hands or virtual limbs, suggest that this analgesic effect can be transferrable to the vision of fake dummy bodies, provided that these are perceived as belonging to one's own body. Nonetheless, further studies are needed to disclose the full potential that bodily illusions might have on pain, especially with the use of IVR. For instance, future investigations making use of dummy bodies or virtual reality set-ups may want to consider much larger sample sizes to gain a greater statistical power, to be able to better understand the contribution that the subjective feeling of ownership over fake body parts has in pain modulation. How the vision of the body and emotional/cognitive factors interact must also be better elucidated. In a recent research article using two different heat-pain intensities, it has been shown that viewing their own body, as compared to viewing a non-corporeal object (a foam block), brought about a report bias toward higher pain judgments in the participants, as well as a reduction in the discriminability between the stimulation intensities. However, seeing the thermode probe approaching the body eliminated the reduction in discriminability (Beck, Làdavas, \& Haggard, 2016). Importantly, the authors reported that such difference was not accounted for differences in stimulation predictability. These findings show the importance played by psychological factors, such as task-related goals and the visual context, in shaping the pain experience during the observation of the body (Beck et al., 2016).

At last but not least, despite the abundance of neuroimaging studies on pain perception, the majority of the studies on pain and the vision of the body during illusory body ownership were conducted without using neuroimaging techniques. 
Future studies on this field may consider the utilization of brain stimulation (for ex. TMS, tDCS) and/or brain imaging techniques (for ex. fMRI, EEG, fNIRS) to shed further light on the identification of a neural web underlying this complex phenomenon.

\section{Acknowledgements}

The author is grateful to Tasha Oneida Lawson for her useful comments.

\section{References}

Apkarian, A. V., Hashmi, J. A., \& Baliki, M. N. (2011). Pain and the brain: specificity and plasticity of the brain in clinical chronic pain. Pain, 152(3 Suppl), S49-64. http://doi.org/10.1016/j.pain.2010.11.010

Artaud, A. (1938). The Theatre and Its Double. Translated by Mary Press., Richards. New York: Grove, 958.

Banakou, D., Groten, R., \& Slater, M. (2013). Illusory ownership of a virtual child body causes overestimation of object sizes and implicit attitude changes. Proceedings of the National Academy of Sciences of the United States of America, 11O(31), 12846-51. http://doi.org/10.1073/pnas.1306779110

Beck, B., Làdavas, E., \& Haggard, P. (2016). Viewing the body modulates both pain sensations and pain responses. Experimental Brain Research. http://doi.org/10.1007/s00221-016-4585-9

Bergström, I., Kilteni, K., \& Slater, M. (2016). First-Person Perspective Virtual Body Posture Influences Stress: A Virtual Reality Body Ownership Study. PloS One, 11(2), e014806o. http://doi.org/10.1371/journal.pone.0148060 
Botvinick, M., \& Cohen, J. (1998). Rubber hands "feel" touch that eyes see. Nature, 391(6669), 756. http://doi.org/10.1038/35784

Botvinick, M., Jha, A. P., Bylsma, L. M., Fabian, S. A., Solomon, P. E., \& Prkachin, K. M. (2005). Viewing facial expressions of pain engages cortical areas involved in the direct experience of pain. NeuroImage, 25(1), 312-9. http://doi.org/10.1016/j.neuroimage.2004.11.043

Campbell, G., Bruno, R., Darke, S., Shand, F., Hall, W., Farrell, M., \& Degenhardt, L. (2015). Prevalence and Correlates of Suicidal Thoughts and Suicide Attempts in People Prescribed Pharmaceutical Opioids for Chronic Pain. The Clinical Journal of Pain. http://doi.org/10.1097/AJP.oooooooooooo0283

Cardini, F., Longo, M. R., \& Haggard, P. (2011). Vision of the body modulates somatosensory intracortical inhibition. Cerebral Cortex (New York, N.Y. : 1991), 21(9), 2014-22. http://doi.org/10.1093/cercor/bhq267

Carter, G. T., Duong, V., Ho, S., Ngo, K. C., Greer, C. L., \& Weeks, D. L. (2014). Side effects of commonly prescribed analgesic medications. Physical Medicine and Rehabilitation Clinics of North America, 25(2), 457-70. http://doi.org/10.1016/j.pmr.2014.01.007

Diers, M., Löffler, A., Zieglgänsberger, W., \& Trojan, J. (2015). Watching your pain site reduces pain intensity in chronic back pain patients. European Journal of Pain (London, England). http://doi.org/10.1002/ejp.765

Diers, M., Zieglgänsberger, W., Trojan, J., Drevensek, A. M., Erhardt-Raum, G., \& Flor, H. (2013). Site-specific visual feedback reduces pain perception. Pain, 154(6), 890-6. http://doi.org/10.1016/j.pain.2013.02.022

Ehrsson, H. H. (2007). The experimental induction of out-of-body experiences. Science (New York, N.Y.), $317(5841), 1048$. http://doi.org/10.1126/science.1142175

Ehrsson, H. H., Spence, C., \& Passingham, R. E. (2004). That's my hand! Activity in premotor cortex reflects feeling of ownership of a limb. Science (New York, N.Y.), 305(5685), 875-7. http://doi.org/10.1126/science.1097011

Gilpin, H. R., Bellan, V., Gallace, A., \& Moseley, G. L. (2014). Exploring the roles of body ownership, vision and virtual reality on heat pain threshold. European Journal of Pain, 18(7), 900-901. http://doi.org/10.1002/j.15322149.2014.483.X

Gilpin, H. R., Moseley, G. L., Stanton, T. R., \& Newport, R. (2015). Evidence for distorted mental representation of the hand in osteoarthritis. Rheumatology (Oxford, England), 54(4), 678-82. http://doi.org/10.1093/rheumatology/keu367

Giummarra, M. J., Georgiou-Karistianis, N., Verdejo-Garcia, A., \& Gibson, S. J. (2015). Feeling the burn: When it looks like it hurts, and belongs to me, it really does hurt more. Consciousness and Cognition, 36, 314-326. http://doi.org/10.1016/j.concog.2015.07.010

González-Franco, M., Peck, T. C., Rodríguez-Fornells, A., \& Slater, M. (2014). A threat to a virtual hand elicits motor cortex activation. Experimental Brain Research, 232(3), 875-87. http://doi.org/10.1007/s00221-013-3800-1

Guterstam, A., \& Ehrsson, H. H. (2012). Disowning one's seen real body during an out-of-body illusion. Consciousness and Cognition, 21(2), 1037-1042. 
http://doi.org/10.1016/j.concog.2012.01.018

Haggard, P., Iannetti, G. D., \& Longo, M. R. (2013). Spatial sensory organization and body representation in pain perception. Current Biology : CB, 23(4), R164-76. http://doi.org/10.1016/j.cub.2013.01.047

Hänsel, A., Lenggenhager, B., von Känel, R., Curatolo, M., \& Blanke, O. (2011). Seeing and identifying with a virtual body decreases pain perception. European Journal of Pain (London, England), 15(8), 874-9. http://doi.org/10.1016/j.ejpain.2011.03.013

Hegedüs, G., Darnai, G., Szolcsányi, T., Feldmann, A., Janszky, J., \& Kállai, J. (2014). The rubber hand illusion increases heat pain threshold. European Journal of Pain (London, England). http://doi.org/10.1002/j.1532-2149.2014.00466.x

Hoffman, H. G., Chambers, G. T., Meyer, W. J. 3rd, Arceneaux, L. L., Russell, W. J., Seibel, E. J., ... Patterson, D. R. (2011). Virtual reality as an adjunctive nonpharmacologic analgesic for acute burn pain during medical procedures. Annals of Behavioral Medicine: A Publication of the Society of Behavioral Medicine, 41(2), 183-191. http://doi.org/10.1007/s12160-010-9248-7

Hoffman, H. G., Doctor, J. N., Patterson, D. R., Carrougher, G. J., \& Furness, T. A. (2000). Virtual reality as an adjunctive pain control during burn wound care in adolescent patients. Pain, 85(1-2), 305-9. Retrieved from http://www.ncbi.nlm.nih.gov/pubmed/10692634

Hoffman, H. G., Meyer, W. J., Ramirez, M., Roberts, L., Seibel, E. J., Atzori, B., ... Patterson, D. R. (2014). Feasibility of Articulated Arm Mounted Oculus Rift Virtual Reality Goggles for Adjunctive Pain Control During Occupational Therapy in Pediatric Burn Patients. Cyberpsychology, Behavior, and Social Networking, 17(6), 397-401. http://doi.org/10.1089/cyber.2014.0058

Hoffman, H. G., Patterson, D. R., \& Carrougher, G. J. (2000). Use of virtual reality for adjunctive treatment of adult burn pain during physical therapy: a controlled study. The Clinical Journal of Pain, 16(3), 244-50. Retrieved from http://www.ncbi.nlm.nih.gov/pubmed/11014398

Hoffman, H. G., Richards, T. L., Coda, B., Bills, A. R., Blough, D., Richards, A. L., \& Sharar, S. R. (2004). Modulation of thermal pain-related brain activity with virtual reality: evidence from fMRI. Neuroreport, 15(8), 1245-8. Retrieved from http://www.ncbi.nlm.nih.gov/pubmed/15167542

Hoffman, H. G., Richards, T. L., Van Oostrom, T., Coda, B. A., Jensen, M. P., Blough, D. K., \& Sharar, S. R. (2007). The analgesic effects of opioids and immersive virtual reality distraction: evidence from subjective and functional brain imaging assessments. Anesthesia and Analgesia, 105(6), 1776-83, table of contents. http://doi.org/10.1213/01.ane.0000270205.45146.db

Hoffman, H. G., Seibel, E. J., Richards, T. L., Furness, T. A., Patterson, D. R., \& Sharar, S. R. (2006). Virtual reality helmet display quality influences the magnitude of virtual reality analgesia. The Journal of Pain : Official Journal of the American Pain Society, 7(11), 843-50.

http://doi.org/10.1016/j.jpain.2006.04.006

Kilteni, K., Grau-Sánchez, J., Veciana De Las Heras, M., Rodríguez-Fornells, A., \& Slater, M. (2016). Decreased Corticospinal Excitability after the Illusion of Missing Part of the Arm. Frontiers in Human Neuroscience, 10, 145. http://doi.org/10.3389/fnhum.2016.00145 
Kilteni, K., Groten, R., \& Slater, M. (2012). The Sense of Embodiment in Virtual Reality. Presence: Teleoperators and Virtual Environments, 21(4), 373-387. http://doi.org/10.1162/PRES_a_o0124

Kilteni, K., Maselli, A., Kording, K. P., \& Slater, M. (2015). Over my fake body: body ownership illusions for studying the multisensory basis of own-body perception. Frontiers in Human Neuroscience, 9, 141. http://doi.org/10.3389/fnhum.2015.00141

Kilteni, K., Normand, J.-M., Sanchez-Vives, M. V, \& Slater, M. (2012). Extending body space in immersive virtual reality: a very long arm illusion. PloS One, $7(7)$, e40867. http://doi.org/10.1371/journal.pone.0040867

Lamm, C., Batson, C. D., \& Decety, J. (2007). The neural substrate of human empathy: effects of perspective-taking and cognitive appraisal. Journal of Cognitive Neuroscience, 19(1), 42-58. http://doi.org/10.1162/jocn.2007.19.1.42

Lanier, J., Minsky, M., Fisher, S., Druin, A. (1989). Virtual Environments And Interactivity: Windows To The Future. ACM Siggraph Panel Proceedings.

Legrain, V., Damme, S. Van, Eccleston, C., Davis, K. D., Seminowicz, D. A., \& Crombez, G. (2009). A neurocognitive model of attention to pain: behavioral and neuroimaging evidence. Pain, 144(3), 230-2. http://doi.org/10.1016/j.pain.2009.03.020

Legrain, V., Mancini, F., Sambo, C. F., Torta, D. M., Ronga, I., \& Valentini, E. (2012). Cognitive aspects of nociception and pain. Bridging neurophysiology with cognitive psychology. Neurophysiologie Clinique/Clinical Neurophysiology, 42(5), 325-336. http://doi.org/10.1016/j.neucli.2012.06.003

Lenggenhager, B., Tadi, T., Metzinger, T., \& Blanke, O. (2007). Video ergo sum: manipulating bodily self-consciousness. Science (New York, N.Y.), 317(5841), 1096-9. http://doi.org/10.1126/science.1143439

Leppink, J. (2015). On causality and mechanisms in medical education research: an example of path analysis. Perspectives on Medical Education, 4(2), 66-72. http://doi.org/10.1007/s40037-015-0174-z

Lewis, E., \& Lloyd, D. M. (2010). Embodied experience: A first-person investigation of the rubber hand illusion. Phenomenology and the Cognitive Sciences, 9(3), 317-339. http://doi.org/10.1007/s11097-010-9154-2

Loeser, J. D., \& Treede, R.-D. (2008). The Kyoto protocol of IASP Basic Pain Terminology. Pain, 137(3), 473-7. http://doi.org/10.1016/j.pain.2008.04.025

Longo, M. R., Betti, V., Aglioti, S. M., \& Haggard, P. (2009). Visually induced analgesia: seeing the body reduces pain. The Journal of Neuroscience: The Official Journal of the Society for Neuroscience, 29(39), 12125-12130. http://doi.org/10.1523/JNEUROSCI.3072-09.2009

Longo, M. R., Iannetti, G. D., Mancini, F., Driver, J., \& Haggard, P. (2012a). Linking pain and the body: neural correlates of visually induced analgesia. The Journal of Neuroscience: The Official Journal of the Society for Neuroscience, 32(8), 2601-2607. http://doi.org/10.1523/JNEUROSCI.4031-11.2012

Longo, M. R., Iannetti, G. D., Mancini, F., Driver, J., \& Haggard, P. (2012b). Linking pain and the body: neural correlates of visually induced analgesia. The Journal of Neuroscience : The Official Journal of the Society for Neuroscience, 32(8), 2601-7. http://doi.org/10.1523/JNEUROSCI.4031-11.2012 
Longo, M. R., Schüür, F., Kammers, M. P. M., Tsakiris, M., \& Haggard, P. (2009). Self awareness and the body image. Acta Psychologica, 132(2), 166-72. http://doi.org/10.1016/j.actpsy.2009.02.003

Lotze, M., \& Moseley, G. L. (2007). Role of distorted body image in pain. Current Rheumatology Reports, 9(6), 488-96. Retrieved from http://www.ncbi.nlm.nih.gov/pubmed/18177603

Maani, C. V, Hoffman, H. G., Morrow, M., Maiers, A., Gaylord, K., McGhee, L. L., \& DeSocio, P. A. (2011). Virtual reality pain control during burn wound debridement of combat-related burn injuries using robot-like arm mounted VR goggles. The Journal of Trauma, 71(1 Suppl), S125-30. http://doi.org/10.1097/TA.obo13e31822192e2

Macaluso, E., \& Maravita, A. (2010). The representation of space near the body through touch and vision. Neuropsychologia, 48(3), 782-95. http://doi.org/10.1016/j.neuropsychologia.2009.10.010

Malloy, K. M., \& Milling, L. S. (2010). The effectiveness of virtual reality distraction for pain reduction: A systematic review. Clinical Psychology Review, 30(8), 1011-1018. http://doi.org/10.1016/j.cpr.2010.07.001

Mancini, F., Longo, M. R., Canzoneri, E., Vallar, G., \& Haggard, P. (2013). Changes in cortical oscillations linked to multisensory modulation of nociception. The European Journal of Neuroscience, 37(5), 768-76. http://doi.org/10.1111/ejn.12080

Mancini, F., Longo, M. R., Kammers, M. P. M., \& Haggard, P. (2011a). Visual distortion of body size modulates pain perception. Psychological Science, 22(3), 325-330. http://doi.org/10.1177/0956797611398496

Mancini, F., Longo, M. R., Kammers, M. P. M., \& Haggard, P. (2011b). Visual distortion of body size modulates pain perception. Psychological Science, 22(3), 325-30. http://doi.org/10.1177/0956797611398496

Martini, M., Kilteni, K., Maselli, A., \& Sanchez-Vives, M. V. (2015). The body fades away: investigating the effects of transparency of an embodied virtual body on pain threshold and body ownership. Scientific Reports, 5, 13948. http://doi.org/10.1038/srep13948

Martini, M., Perez-Marcos, D., \& Sanchez-Vives, M. V. (2013). What Color is My Arm? Changes in Skin Color of an Embodied Virtual Arm Modulates Pain Threshold. Frontiers in Human Neuroscience, 7, 438. http://doi.org/10.3389/fnhum.2013.00438

Martini, M., Perez-Marcos, D., \& Sanchez-Vives, M. V. (2014). Modulation of pain threshold by virtual body ownership. European Journal of Pain (London, England). http://doi.org/10.1002/j.1532-2149.2014.00451.x

Martini, M., Perez-Marcos, D., \& Sanchez-Vives, M. V. (2015). Author's reply to the commentary by Gilpin et al. European Journal of Pain (London, England), 19(1), 143-4. http://doi.org/10.1002/ejp.606

Maselli, A., \& Slater, M. (2013). The building blocks of the full body ownership illusion. Frontiers in Human Neuroscience, 7, 83. http://doi.org/10.3389/fnhum.2013.00083

Mayer, A., Kudar, K., Bretz, K., \& Tihanyi, J. (2008). Body schema and body awareness of amputees. Prosthetics and Orthotics International, 32(3), 363-82. 
http://doi.org/10.1080/03093640802024971

Medina, J., \& Coslett, H. B. (2010). From maps to form to space: touch and the body schema. Neuropsychologia, 48(3), 645-54.

http://doi.org/10.1016/j.neuropsychologia.2009.08.017

Moayedi, M., \& Davis, K. D. (2013). Theories of pain: from specificity to gate control. Journal of Neurophysiology, 109(1), 5-12.

http://doi.org/10.1152/jn.00457.2012

Mohan, R., Jensen, K. B., Petkova, V. I., Dey, A., Barnsley, N., Ingvar, M., ... Ehrsson, H. H. (2012). No Pain Relief with the Rubber Hand Illusion. PLoS ONE, 7(12), e52400. http://doi.org/10.1371/journal.pone.0052400

Morgan, H. L., Turner, D. C., Corlett, P. R., Absalom, A. R., Adapa, R., Arana, F. S., ... Fletcher, P. C. (2011). Exploring the impact of ketamine on the experience of illusory body ownership. Biological Psychiatry, 69(1), 35-41.

http://doi.org/10.1016/j.biopsych.2010.07.032

Moseley, G. L., Parsons, T. J., \& Spence, C. (2008). Visual distortion of a limb modulates the pain and swelling evoked by movement. Current Biology: $C B$, 18(22), R1047-1048. http://doi.org/10.1016/j.cub.2008.09.031

Mouraux, A., Diukova, A., Lee, M. C., Wise, R. G., \& Iannetti, G. D. (2011). A multisensory investigation of the functional significance of the "pain matrix". NeuroImage, 54(3), 2237-49.

http://doi.org/10.1016/j.neuroimage.2010.09.084

Mouraux, A., \& Iannetti, G. D. (2009). Nociceptive laser-evoked brain potentials do not reflect nociceptive-specific neural activity. Journal of Neurophysiology, 101(6), 3258-3269. http://doi.org/10.1152/jn.91181.2008

Osumi, M., Imai, R., Ueta, K., Nakano, H., Nobusako, S., \& Morioka, S. (2014). Factors associated with the modulation of pain by visual distortion of body size. Frontiers in Human Neuroscience, 8, 137. http://doi.org/10.3389/fnhum.2014.00137

Osumi, M., Imai, R., Ueta, K., Nobusako, S., \& Morioka, S. (2014). Negative body image associated with changes in the visual body appearance increases pain perception. PloS One, 9(9), e107376.

http://doi.org/10.1371/journal.pone.0107376

Peck, T. C., Seinfeld, S., Aglioti, S. M., \& Slater, M. (2013). Putting yourself in the skin of a black avatar reduces implicit racial bias. Consciousness and Cognition, 22(3), 779-87. http://doi.org/10.1016/j.concog.2013.04.016

Peled, A., Ritsner, M., Hirschmann, S., Geva, A. B., \& Modai, I. (2000). Touch feel illusion in schizophrenic patients. Biological Psychiatry, 48(11), 1105-8. Retrieved from http://www.ncbi.nlm.nih.gov/pubmed/11094144

Peters, M. L. (2015). Emotional and Cognitive Influences on Pain Experience. Modern Trends in Pharmacopsychiatry, 30, 138-52. http://doi.org/10.1159/000435938

Petkova, V. I., \& Ehrsson, H. H. (2008). If I were you: perceptual illusion of body swapping. PloS One, 3(12), e3832. http://doi.org/10.1371/journal.pone.0003832

Petkova, V. I., Khoshnevis, M., \& Ehrsson, H. H. (2011). The perspective matters! Multisensory integration in ego-centric reference frames determines full-body 
ownership. Frontiers in Psychology, 2, 35. http://doi.org/10.3389/fpsyg.2011.00035

Preston, C., \& Newport, R. (2011). Analgesic effects of multisensory illusions in osteoarthritis. Rheumatology (Oxford, England), 5o(12), 2314-5. http://doi.org/10.1093/rheumatology/ker104

R, M. (1990). Phantom limbs and the concept of a neuromatrix. Trends in Neurosciences, 13.(3), 88-92.

Ramachandran, V. S., Brang, D., \& McGeoch, P. D. (2009). Size reduction using Mirror Visual Feedback (MVF) reduces phantom pain. Neurocase, 15(5), 35736o. http://doi.org/10.1080/13554790903081767

Ramachandran, V. S., \& Rogers-Ramachandran, D. (1996). Synaesthesia in Phantom Limbs Induced with Mirrors. Proceedings of the Royal Society B: Biological Sciences, 263(1369), 377-386. http://doi.org/10.1098/rspb.1996.0058

Romano, D., Llobera, J., \& Blanke, O. (2015). Size and viewpoint of an embodied virtual body impact the processing of painful stimuli. The Journal of Pain : Official Journal of the American Pain Society. http://doi.org/10.1016/j.jpain.2015.11.005

Romano, D., \& Maravita, A. (2014). The visual size of one's own hand modulates pain anticipation and perception. Neuropsychologia, 57, 93-100. http://doi.org/10.1016/j.neuropsychologia.2014.03.002

Saarela, M. V, Hlushchuk, Y., Williams, A. C. de C., Schürmann, M., Kalso, E., \& Hari, R. (2007). The compassionate brain: humans detect intensity of pain from another's face. Cerebral Cortex (New York, N.Y. : 1991), 17(1), $230-7$. http://doi.org/10.1093/cercor/bhj141

Sanchez-Vives, M. V, \& Slater, M. (2005). From presence to consciousness through virtual reality. Nature Reviews. Neuroscience, 6(4), 332-339. http://doi.org/10.1038/nrn1651

Sanchez-Vives, M. V, Spanlang, B., Frisoli, A., Bergamasco, M., \& Slater, M. (2010). Virtual hand illusion induced by visuomotor correlations. PloS One, 5(4), e10381. http://doi.org/10.1371/journal.pone.0010381

Sanchez-Vives, M. V., \& Slater, M. (2005). From presence to consciousness through virtual reality. Nature Reviews Neuroscience, 6(4), 332-339.

Schweinhardt, P., \& Bushnell, M. C. (2010). Pain imaging in health and disease--how far have we come? The Journal of Clinical Investigation, 120(11), 3788-97. http://doi.org/10.1172/JCI43498

Senkowski, D., Höfle, M., \& Engel, A. K. (2014). Crossmodal shaping of pain: a multisensory approach to nociception. Trends in Cognitive Sciences, 18(6), 31927. http://doi.org/10.1016/j.tics.2014.03.005

Serino, A., \& Haggard, P. (2010). Touch and the body. Neuroscience and Biobehavioral Reviews, 34(2), 224-36. http://doi.org/10.1016/j.neubiorev.2009.04.004

Siedlecka, M., Klimza, A., Łukowska, M., \& Wierzchoń, M. (2014). Rubber hand illusion reduces discomfort caused by cold stimulus. PloS One, 9(10), e109909. http://doi.org/10.1371/journal.pone.0109909

Slater, M., Perez-Marcos, D., Ehrsson, H. H., \& Sanchez-Vives, M. V. (2008). 
Towards a digital body: the virtual arm illusion. Frontiers in Human Neuroscience, 2, 6. http://doi.org/10.3389/neuro.09.006.2008

Slater, M., Perez-Marcos, D., Ehrsson, H. H., \& Sanchez-Vives, M. V. (2009). Inducing illusory ownership of a virtual body. Frontiers in Neuroscience, 3(2), 214-20. http://doi.org/10.3389/neuro.01.029.2009

Slater, M., Spanlang, B., Sanchez-Vives, M. V, \& Blanke, O. (2010). First person experience of body transfer in virtual reality. PloS One, 5(5), e10564. http://doi.org/10.1371/journal.pone.0010564

Tarr, M. J., \& Warren, W. H. (2002). Virtual reality in behavioral neuroscience and beyond. Nature Neuroscience, 5 Suppl, 1089-92. http://doi.org/10.1038/nn948

Tipper, S. P., Lloyd, D., Shorland, B., Dancer, C., Howard, L. A., \& McGlone, F. (1998). Vision influences tactile perception without proprioceptive orienting. Neuroreport, 9(8), 1741-4. Retrieved from http://www.ncbi.nlm.nih.gov/pubmed/9665593

Triberti, S., Repetto, C., \& Riva, G. (2014). Psychological factors influencing the effectiveness of virtual reality-based analgesia: a systematic review. Cyberpsychology, Behavior and Social Networking, 17(6), 335-45. http://doi.org/10.1089/cyber.2014.0054

Tsay, A., Allen, T. J., Proske, U., \& Giummarra, M. J. (2015). Sensing the body in chronic pain: a review of psychophysical studies implicating altered body representation. Neuroscience and Biobehavioral Reviews, 52, 221-32. http://doi.org/10.1016/j.neubiorev.2015.03.004

Valenzuela-Moguillansky, C., Bouhassira, D., \& O’Regan, J. K. (2011). Role of Body Awareness. Journal of Consciousness Studies, 9-10, 110-142. Retrieved from http://www.ingentaconnect.com/content/imp/jcs/2011/ooooo018/foo20009/ art00006

Valeriani, M., Betti, V., Le Pera, D., De Armas, L., Miliucci, R., Restuccia, D., ... Aglioti, S. M. (2008). Seeing the pain of others while being in pain: a laserevoked potentials study. NeuroImage, 4O(3), 1419-28. http://doi.org/10.1016/j.neuroimage.2007.12.056

Vierck, C. J., Whitsel, B. L., Favorov, O. V, Brown, A. W., \& Tommerdahl, M. (2013). Role of primary somatosensory cortex in the coding of pain. Pain, 154(3), 33444. http://doi.org/10.1016/j.pain.2012.10.021

Wager, T. D., Atlas, L. Y., Lindquist, M. A., Roy, M., Woo, C.-W., \& Kross, E. (2013). An fMRI-based neurologic signature of physical pain. The New England Journal of Medicine, 368(15), 1388-97. http://doi.org/10.1056/NEJMoa1204471

Wesslein, A.-K., Spence, C., \& Frings, C. (2014). Vision affects tactile target and distractor processing even when space is task-irrelevant. Frontiers in Psychology, 5, 84. http://doi.org/10.3389/fpsyg.2014.00084 


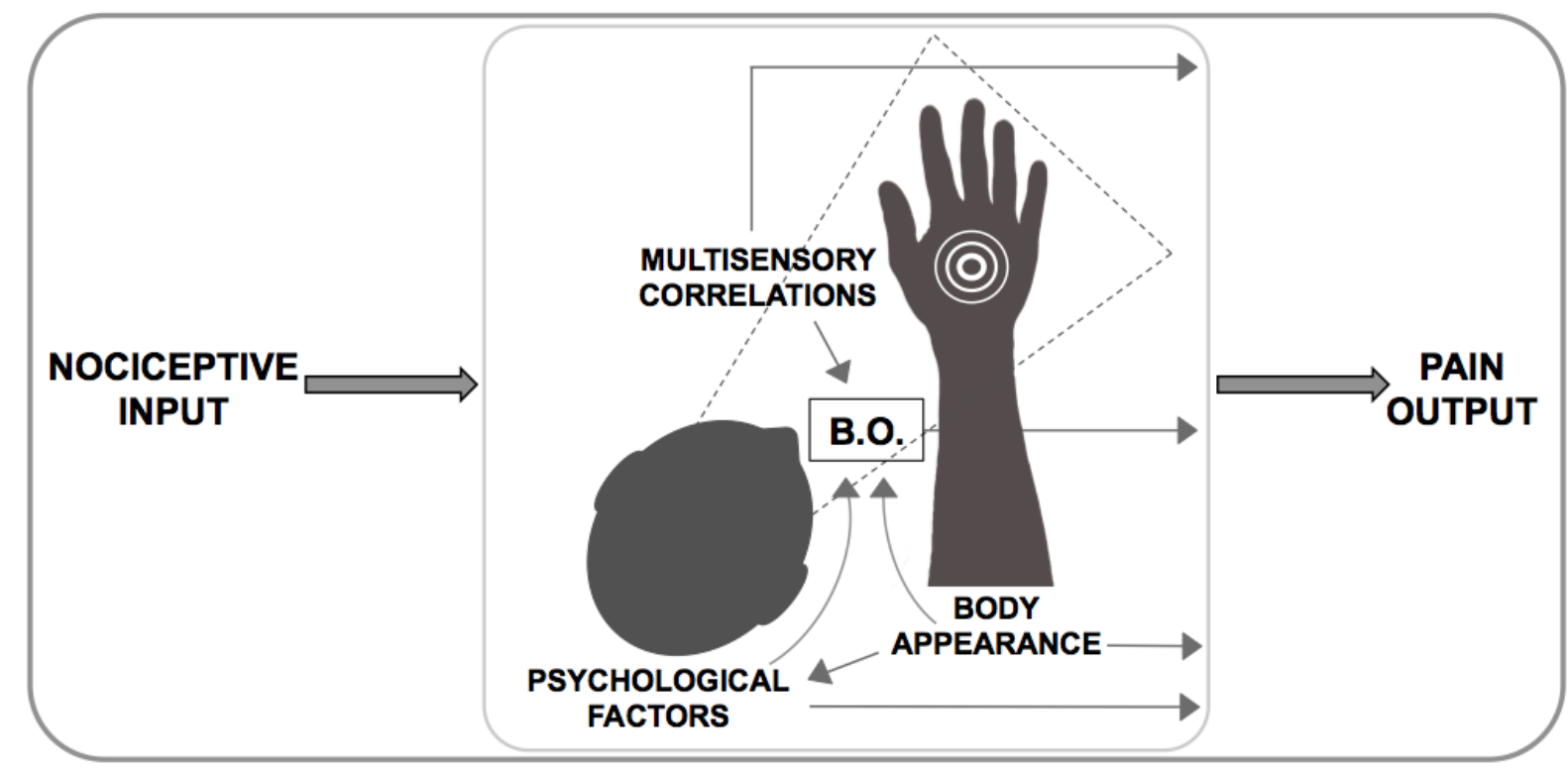

Fig. 1

Schematic representation of the factors involved in pain modulation during body ownership (B.O.) paradigms: multisensory correlations facilitate the onset of B.O. over a fake body part, but multisensory cues may also modulate pain perception. The appearance of the body may regulate B.O. levels but also affect psychological factors such as body image and affect pain perception. Psychological factors embrace both cognitive (e.g. attentional resources, expectancy and appraisal) and emotional factors (e.g. positive or negative mood). Both body appearance and multisensory processing are strictly related to the affective/cognitive domain of the "psychological factors" group, but here are depicted as separate factors for the sake of clarity, because they are often studied as separate factors in B.O. experiments, and may contribute to shape the pain experience independently. 